to people who have not had a heart attack," he does not suggest that those who have had a heart attack ought to discontinue their lipid-lowering drugs. Hadler's warning to the well is that the aggressive marketing of medications, aimed at patients and physicians alike, often fails to mention that the research on which its claims are based was conducted on a population of people quite unlike themselves (i.e., sick people). Hadler also wants his readers to know that data from secondary prevention studies cannot necessarily be extrapolated to primary prevention; that is, just because "studies" have shown that my grandfather who had a myocardial infarction might benefit from taking an aspirin a day, it does not follow that I will benefit from taking an aspirin with my morning caffeine.

Having said that, if I have a headache, caffeine and aspirin (or acetaminophen) might be just the ticket. And this brings me to the second, more compelling, theme of Hadler's book. "We cannot live," he writes,

without heartache and backache, heartburn and headache, unfamiliar bowel function, peculiar sensations, days in the doldrums, realizations of physical limits, and myriad other predicaments.

Hadler bemoans the thinking that has "elevated medicine to be the arbiter of normalcy," and he is at pains to convince his readers, in the face of much "information" to the contrary, that to "be well is to be able to cope with morbid episodes," not to be free of symptoms.

Not every symptom, that is, needs to be fixed or even investigated. I think I would be hard pressed to find a physician to disagree with this. But in a manner not unlike Kassirer's, Hadler seems to imply that many of us lack the ability to appreciate nuance. It is his somewhat bitter-sounding contention that we all are held captive by "the belief that there must be a disease underlying every illness, [and are] seduc[ed] to assume that any demonstrable coincident abnormality, or difference, is the likely culprit." Be wary of your doctor, he suggests, lest he or she dangerously insist on fixing what isn't broken.
Now, to be fair (if a little defensive), I am fortunate to be part of a clinic (and I hope a community) where the distinction between illness and disease is understood, and indeed where kind reassurance and gentle handholding are valued as therapeutic manoeuvres. Although Hadler warns that a "physician can arrange a cardiac catheterization far more readily than [she or] he can manage the considerable time to discuss why it may not be necessary," I wonder, as I did throughout his book, whether it is patients or physicians who drive the medicalizing machine.

To be sure, it's a chicken-and-egg sort of conundrum. I'm tempted to take the easy way out and blame the big drug companies (even as I eat their sandwiches). More likely, though, I think I will continue to muddle my way through grey ambiguities, while I struggle to render the "evidence" from large (arguably compromised) population studies germane to the lives of my individual patients, many of whom I need more than they need me.

\section{Edward E. St. Godard \\ PGY1 \\ Family Medical Centre \\ University of Manitoba \\ Winnipeg, Man.}

\title{
Une heureuse union
}

went into her room and was asked, "What's the French for 'gallbladder'?" The nice francophone lady with the positive Murphy sign had been trying to explain her problem to her husband. He'd been at her bedside since she was admitted, wearing a look of tender concern the whole time. But he had less English than she did and had not understood our explanations of what was the matter.

Later I realized that if she couldn't name the organ in her first language, she likely hadn't understood what "gallbladder" meant, either. At the time, though, all I could think was, "What's the French for 'gallbladder.' I dunno ... le gallbladder?" Four and a half years of high school French, and this was my best guess.

Looking for an excuse, any excuse, not to go to the OR to watch one more laparoscopic cholecystectomy, I decided to find the answer. There was a francophone nurse on the ward, but she wasn't working that day. One of the custodial staff spoke some French, but not enough: he said he'd call his grandfather and ask him. I protested, feebly, that this was not important enough to bother anyone's Grampa about. But when the guy came back with his grandfather's answer, I happily thanked him for it.

On my way back to my patient's room, I practised pronunciation in my head. I delivered a pre-emptory apology for whatever injury I was about to do to their language and then told them how to say "gallbladder" in French.

The husband's face lit up with long-awaited understanding. "Ahhh ... vésicule biliare!" he exclaimed. He then turned to his wife, and his expression changed from happy comprehension to the sweet worry I was used to seeing. A moment later, though, his face changed again. I found his new expression to be strangely comforting; I guessed that it marked the return of some of the normalcy that had been taken from their marriage by her illness.

It was an apparently well-practised look of mild annoyance. It seemed to say, in French even I could understand, "Well, why didn't you just say that?"

\section{Paul Moorehead}

Pediatrics Resident

Memorial University of Newfoundland

St. John's, Nfld. 